\title{
The Neutrality of the State and Its Justification In Rawls and Mill
}

John Patrick Rudisill

The George Washington University

Introduction

In this essay I am concerned with drawing instructive parallels between the justifications of a principle of neutrality that occur in John Rawls's political liberalism and in John Stuart Mill's substantive liberalism. For both Rawls and Mill, the principle of neutrality is meant to be a crucial part of the claim to legitimacy for their preferred state. I begin with some brief comments about (1) the problem of political legitimacy as it is understood by modern political philosophers and (2) the concept of neutrality and how it is readily suggested by the modern formulation of the problem of political legitimacy. Next, I show how the theories of Rawls and Mill share striking structural similarity in terms of their justification of a principle of neutrality. Moreover, there are points at which the structure of the principle of neutrality is in important respects the same for both philosophers. However, once the parallels are drawn we can isolate the important dissimilarity of these views. On the basis of the distinguishing features of the two approaches, it is argued that there is good reason to reject that of Rawls.

\section{The Problem of Political Legitimacy and the Role of Neutrality}

The spirit of tolerance and disdain for coercive force are crucial motivators of modern politics and social structuring. A person would be hard-pressed to find-either within the literature of modern political philosophy or amongst the citizens of our modern society - any argument that is taken seriously that suggests that the basis of a state's legitimacy has nothing to do with the acceptance (or acceptability) of that state by its (would-be) subjects. Even amongst philosophers who are sharply critical of "contract theories" there is an acknowledgment that a state is not legitimate when its 
presence could be maintained only by coercive force against its subjects. It is also widely acknowledged that amongst the citizens of a modern state there will be a wide range of actually held and reasonable conceptions of the "good life." Together, this suggests that the legitimacy of a modern state hinges on its being acceptable to a citizenry that is marked by diversity. The task for modern political philosophers has been to develop a conception of politics and political institutions that passes this test for legitimacy. Many of the favored candidate conceptions have relied on various formulations of a principle of neutrality. Making such a principle a central feature of one's political theory seems obvious once the problem of political legitimacy is understood in this way.

Neutrality' is sought under the condition of perceived disagreements of judgment. The judgments, moreover, need to be judgments of value or judgments of states of affairs where the judge values being right (is not indifferent to his making a correct judgment or not). A final condition for the seeking of neutrality is that there is recognized a legitimacy to each of the discrepant judgments so that it is decided that each of the judgments are, in some sense, rightfully made and endured. The legitimacy of discrepant judgments is grounded in the supposition that either (a) there can be more than one right judgment made, (b) there is no right or wrong judgment to be made in the matter, or (c) there is a sufficient degree of uncertainty regarding the matter being judged that it is deemed unwarranted to label one of the judgments illegitimate. Liberal political theorists find these conditions present in human affairs and thus advance political theories that strive towards neutrality.

The classic and perhaps original moment of liberal neutrality involves the case for religious toleration. In the face of stark disagreements between different segments of the population regarding matters of religion, liberals came to argue that the state cannot rightfully endorse or institutionalize a particular judgment or set of judgments on these matters (where such endorsement would involve mandating that all citizens accept these judgments). Because of the passionate commitment individuals have to their religious beliefs and because the final truth of these matters is so difficult to settle in any way that satisfies all parties, the state that 
is to govern these individuals must remain neutral with respect to judgments of religion.

Diversity in religious views, however, is far from being the only diversity found amongst members of modern society. Citizens of modern states vary racially and ethnically, from region to region, along the lines of economic class, as a result of membership in different voluntary organizations, and out of natural human idiosyncrasies. We are diverse in what we value and we value things differently because of our diversity. Many of the differing judgments of value found in a diverse citizenry are held quite dearly to those who make the judgments. In many cases the judgments of value are partly constitutive of the citizens' individual selfconceptions. A judgment of value is partly constitutive of a citizen's individual self-conception whenever it is the case that if the citizen were to be asked to state the features that make her the distinct person she is, she would not be able to do so in any way that she would find sufficiently comprehensive without some reference to her holding these judgments of value. There exists, in modern society, a tremendous variety of these judgments. However, even where such judgments differ they are frequently each regarded as legitimate because they are judgments that (a) can each be right, (b) can't be right or wrong, or (c) because they are judgments the truth of which is not satisfactorily established. Given their legitimacy, liberal theorists maintain that the state is to remain neutral with respect to them.

\section{The Justification of Neutrality: General Strategies}

So, we seek neutrality in our politics and our political theorizing in part because we are aware of the reasonable disagreement between citizens of our modern society regarding judgments of value. Something tells us that a neutral stance is the right stance to take in such a situation. But what makes it right? In many instances, a course of action or particular policy is justified on the grounds that the action or policy will promote some value. In this situation, however, this mode of justification presents us with some difficulty. After all, what it is that we are trying to justify is neutrality and this neutrality is with respect to different values. When you justify 
some policy on the basis of some value it promotes it is hardly the case that the policy is neutral with respect to that justificatory value.

For those theorists who are committed to a strong formulation of the "priority of the right" thesis, there is thought to be a preferable alternative mode of justification. That which is right, say such theorists, is never given its justification on the basis of its promotion of any good. Right is right whether it promotes or hinders the good or even if, as a matter of circumstance, it has positively harmful consequences. For these theorists, the principle of neutrality might best be understood as either an alternative formulation of the priority of right thesis or the supreme principle recommended by it. The motivation behind the assertion of the priority of the right is a powerful one. By separating the right from any independent notion of the good, morality (which is concerned with the right) can be understood as unconditionally binding: necessary rather than contingent. Ronald Dworkin's thought is the best example of a neutralist liberalism committed to the strong formulation of the priority of the right thesis. Exactly how this alternative mode of justification is to be understood is difficult to make clear. While I acknowledge the significance of this alternative in the history of addressing this problem, it is not one I shall consider more in this paper.

Making a distinction between types of value is a general strategy shared by two distinct sorts of neutralist liberals in dealing with the problem of justifying neutrality. Distinguishing between types of value is supposed to reveal how it is that there is no incoherence involved with relying on values for the justification of the principle that demands neutrality towards conceptions of value. The neutrality defended is to be understood as being with respect to values of type $A$. This neutrality is not threatened when it is justified on the basis of values of type $B$.

\section{The Strategy Employed: Mill and Rawls}

One version of this general approach is found in the work of John Stuart Mill. Mill maintained that happiness is the one supreme good and, thus, that we ought to maximize the amount of happiness in the world. He further understood human nature to be such that 
true happiness consists in living autonomously. Mill, in some of the most eloquent passages of $O n$ Liberty, forcefully praises original (self) expression as the central component of a good human life. Liberty ought to be defended, argues Mill, not only because it is a necessary condition for our being able to finally discover and rightfully appreciate significant and elusive truths about the world, but also on the basis of an already recognized truth: individuality, 'peculiarity of taste,' and 'eccentricity of conduct,' are essential components of human flourishing and happiness. Mill understood neutrality as necessary with respect to the variety of ways persons can lead their lives such that they manifest the recognized good for humans. There was no need to be neutral regarding competing understandings of supreme value, but rather only regarding the variety of life-plans through which the one supreme value might be realized. The diversity that must be respected by the states adopting a neutral stance is a diversity of ways of living that are each constitutive of the supreme good. The two types of good for Mill, then, are (1) the supreme good of happiness understood as autonomous living and (2) the good of lives lived such as to realize the supreme good. The latter good is plural in its nature and it is with respect to this plurality that the state ought to remain neutral. This neutrality is justified, however, on the grounds that each of the allowable plans of life constituting this plurality have in common their being realizations of the supreme good.

Most deontologically minded political theorists like Rawls want to distance themselves from this Millean way of establishing the legitimacy of the state because they understand Mill's supreme value - the one that justifies his version of neutrality - as being itself controversial. Insofar as there can be reasonable disagreement with respect to Mill's understanding of what is of supreme value as well as with respect to what might best lead to the realization of that value we have reason to seek out an even more comprehensive neutrality. So Mill would apparently fail to be neutral enough for Rawls. But Rawls thinks that neutrality is somehow the appropriate expression of justice as faimess and that certain types of good supply the justification for justice as fairness. Thus Rawls, like Mill, is to be understood as employing the general strategy described above for justifying neutrality. For Rawls, though, the distinction between 
types of value is quite different from that found in Mill.

The Rawlsian distinction claims that on the one hand we have "value" understood in the sense of principles of right. These sorts of values, call them political values, place limits on the ways in which citizens are able to act in pursuing their own ends. Autonomy, tolerance and equality are paradigm examples of such values for liberals. To this list, Rawls adds (among others) goodness as rationality, primary goods, and the good of a well-ordered society. These are values in that the limits they set provide a level playing field for the members of a diverse citizenry. On the other hand we have "value" understood as that which serves as an end for citizens. This latter sense of value is what makes the good in a given conception of the good life. Values of this sort, call them personal values, are the source of difference in a pluralistic society. Rawls's liberal argument for neutrality, then, is the argument for a political theory that defends a model of the state that is neutral with respect to personal value. The justification of this neutrality is made on the basis of political values. According to Rawls, the principle of neutrality in political theory is the expression of the priority of right. ${ }^{2}$ However, his formulation of the thesis of the priority of right is a weak formulation since it allows for the use of political values in a justificatory role. Strong formulations of the thesis reject the use of any conception of the good in such a justificatory role.

\section{The Structure of the Principle of Neutrality}

The non-neutral state, given Rawls's view, is one which bases its political decisions on some particular comprehensive conception of the good life (personal value) and thereby eschews any acknowledgment of the priority of the right. From Rawls's neutralist liberal perspective, given the diversity of actually held conceptions of the good life, citizens are not treated fairly whenever some preferred conception informs and justifies the character of the state. A neutral state on the other hand avoids making any of its decisions for the reason that the decision will promote some such conception of the good and thereby treats its diverse citizens fairly. 
This is one of a variety of ways to sharpen the vague concept of neutrality. Rawls, for example, distinguishes between procedural neutrality and neutrality of aim. These are specified in the following way. Neutrality might be understood as involving a procedure (say for establishing principles to abide by in some endeavor - like creating a just society) that is justified on the basis of no values at all or on the basis of values shared by and thus neutral between all whose interests will be affected by the procedure. Neutrality might also be understood in terms of aims (say of the institutions and policies of a state). A policy is neutral in its aims when the reasons for which it is put into place do not include its promoting or being likely to promote some particular comprehensive conception of the good.3 Rawls's "justice as fairness" is understood as neutral in both of these senses. It is procedurally neutral:

...in virtue of its being a political conception that aims to be the focus of an overlapping consensus. That is, the view as a whole hopes to articulate a public basis of justification for the basic structure of a constitutional regime working from fundamental intuitive ideas implicit in the public political culture and abstracting from comprehensive religious, philosophical, and moral doctrines. 4

Justice as fairness:

...also hopes to satisfy neutrality of aim in the sense that the basic institutions and public policy are not to be designed to favor any comprehensive doctrine. 5

Justice as fairness is understood in terms of the central commitment to neutrality in the sense of neutrality of aim. It is itself given a neutral justification that takes the form of a procedural neutrality.

There is a clear sense in which we can further understand Mill's approach as parallel to that of Rawls. Mill's conception of justice involves a commitment to a principle of neutrality demanding that 
the state not favor some particular way of life. Thus, he is defending neutrality understood in a way that is structurally similar to that of Rawls's neutrality of aim.6 However, whereas the neutrality of aim in Rawls's theory is a neutrality with respect to comprehensive conceptions of the good, that which is found in Mill's theory is with respect to those plans of life that are understood as being realizations of the summum bonum. We can also understand Mill's defense of this neutrality as a species of procedural neutrality, although to do so we must interpret that conception of neutrality in a way that Rawls does not. The conception of procedural neutrality, recall, is a conception understood as involving a procedure that is justified on the basis of no values at all or on the basis of values shared by and thus neutral between all whose interests will be effected by the procedure. As Rawls understands this notion of neutrality, to speak of some value(s) as shared and thus neutral is to speak of values that are actually, commonly held or consciously acknowledged. In order to characterize Mill's defense of neutrality with respect to plans of life as involving a species of procedural neutrality we must allow that the crucial sharing of values needn't involve common acknow'ledgment. To say that the justificatory value Mill relies on (the summum bonum) is neutral because shared is to say that this value is a value for everyone equally whether they acknowledge this fact or not. ${ }^{7}$ Thus, the value that Mill refers to in order to justify his principle of neutrality of aim (the summum bonum of happiness understood as consisting in autonomous living) is, from within Mill's approach, neutral because it is the supreme value for everyone.

\section{The Dissimilarity of the Two Theories}

The distinction, drawn by Rawls, between personal and political value is not meant to be understood as (like Mill's) a distinction between the summum bonum conceived in abstraction and the various, particular life plans which instantiate the summum bonum. Liberals who rely on the personal / political value distinction wish to distance their political theories from a commitment to any claim about the intrinsic or supreme value of anything. Instead, the key to this distinction lies (at least in part) in the understanding of 
political values as being (relatively or sufficiently) uncontroversial whereas personal values are the subject of a great deal of reasonable controversy. The concept of political values, as values that set limits on the ways in which citizens can pursue personal values such that each enjoys fair opportunity in their pursuit, is meant to be a conception of values that will ideally be acknowledged by all citizens. These values, it is claimed, are already neutral values because no matter what the personal values a person might hold, she will recognize the political values as at least consistent with and at best positively beneficial to the realization of her personal values. In Rawls's language, the political values are understood as those that would be found in an overlapping consensus of divergent comprehensive conceptions of the good.

There are, though, considerations that require that the Rawlsian account (as I have presented it thus far) incorporate significant qualifications and in fact Rawls himself recognizes this. Yet, once it is conceded that these qualifications are necessary, it starts to become apparent that the political values are (in one important sense) no more comprehensively neutral than is Mill's summum bonum. Once we appreciate this, we are in a better position to judge the crucial difference between Rawls's political liberalism and Mill's substantive liberalism. This crucial difference, I shall maintain, is not one that rightly recommends Rawls's approach.

In order to understand the necessary qualifications of the Rawlsian account and the consequences that follow from these, it is instructive to consider the conception of the good for humans that Mill took to be most antithetical to his own preferred conception. The conception I am referring to is the "Calvinistic theory," according to which:

...the one great offence of man is self-will. All the good of which humanity is capable is comprised in obedience. You have no choice; thus you must do, and not otherwise: 'whatever is not a duty, is a $\sin$ '. Human nature being radically corrupt, there is no redemption for any one until human nature is killed within him. To one holding this theory of life, crushing out any of the human faculties, 
capacities and susceptibilities, is no evil: man needs no capacity, but that of surrendering himself to the will of God: and if he uses any of his faculties for any other purpose but to do that supposed will more effectually, he is better without them. ${ }^{8}$

If we assume that, in addition to the above characterization, this conception also understands general obedience as necessary for the realization of the good (so that I am not satisfied just so long as $I$ avoid exercising my capacities but only when this avoidance characterizes the population generally) we could conclude that this conception is not going to contain within it an acceptance of the political values on the basis of which (for Rawls) the principle of neutrality is defended.

From within the "Calvinistic theory," the disagreement about the nature of the good, which is a distinguishing characteristic of modern society, will not be regarded as a reasonable disagreement. The "fact of pluralism" will be rejected as something towards which societies ought to be accommodating. The very idea of concerning oneself with the problem of trying to make the character of the state such that it is acceptable to some variety of heathens is an affront to this conception. The political values Rawls relies on: goodness as rationality, political virtues, the good of the well ordered society (to name three), are each understood in terms that locate them equally within the variety of heathen comprehensive conceptions of the good that is constitutive of the fact of pluralism. Understood in these terms, these political values will not be located within the Calvinistic theory. For example, Rawls begins with the presupposition that the "fact of pluralism" which characterizes modern societies is a fact that ought to be accommodated. The plurality, moreover, that he wishes to accommodate is a plurality of reasonable comprehensive conceptions of the good. One of the political values that he relies on to justify his neutrality of aim is the idea of goodness as rationality. Rawls must understand (given that he accepts a plurality of reasonable comprehensive conceptions of the good) rationality as being consistent with substantive disagreement about how humans are to lead their lives. If this is to be a part of the content of the conception of rationality, the Calvinist 
is not going to recognize rationality as a good but rather as a primary source of evil. However, if the Calvinist understands rationality as a good he will not see it as a general trait of humans that is shared equally by persons who are in disagreement about what is valuable in human life. It follows that the political value of goodness as rationality is not neutral with respect to all actual (let alone possible) comprehensive conceptions of the good. There are some conceptions that simply do not share in the overlap in which the political values are located. This is not something of which Rawls is unaware, nor does he find this to be a problem for his theory.

Why is it that the Calvinistic theory, for example, is not one towards which our state should be neutral? For Rawls the answer lies in its not being one of the permissible comprehensive conceptions. But what is it that determines the permissibility and impermissibility of a conception? The answer to this is that a conception is permissible in as much as it contains respect for the principles of justice. This is to say that those conceptions that overlap in just the right way are permissible in virtue of their overlapping as they do and those that are not a part of the overlap are impermissible in virtue of their failing to have any significant part in common with the rest. Thus the Calvinistic conception is an impermissible conception since it does not recognize the political values that are necessary for Rawls's justification of his principle of neutrality of aim. It might be thought that this circularity is a great problem for Rawls's account. Rawls instead thinks that the circularity is not a problem since parameters are already set for his political conception of justice by certain historical facts constitutive of the subject of his theory. Given that his theory is to be one for a modern, western, constitutional democratic regime, Rawls has no problem with accepting that certain comprehensive conceptions of the good - those, like the Calvinist theory, that are in important respects incompatible with the constitutional democratic regime are ruled out right from the start.

Notice, though, that the neutrality Rawls establishes for his theory comes with a high price tag. Rawls argues that the reliance on certain conceptions of good (political good) for a justification of justice as fairness does not entail that justice as fairness is a form of perfectionism. The way he avoids this conclusion is through 
a characterization of the truth condition for the claims to goodness as involving only their actual acceptance within a certain sociocultural environment.

We can see this (that reliance on these ideas of the good needn't lead to perfectionism) once we are clear about the political conception of justice...ideas of the good may freely be introduced so long as they are political ideas, that is, so long as they belong to a reasonable political conception of justice for a constitutional regime. This allows us to assume that they are shared by citizens and do not depend on any particular comprehensive doctrine. 9

To say that it is true that these goods are goods depends not at all on some comprehensive doctrine establishing the case since it is to say nothing more than that these goods are accepted as goods by the sorts of citizens who make up the state being structured. The Calvinistic theory of the good will not thrive but this fact does not suggest any culpable failure to be neutral since for any state some conceptions will not fit in. This is an unavoidable consequence.

Another way of avoiding the circularity of defining permissible and impermissible conceptions of the good would be to opt instead for an account of the impermissibility of a comprehensive conception as grounded in the conception's being inconsistent with or positively in opposition to the summum bonum. This is the way in which impermissible conceptions are understood in the Millean theory. The only advantage over this Millean approach that Rawls could be understood to have gained in his political liberalism is the advantage of not having to defend the truth of any claim as to the value of something, say that of autonomy, in any sense stronger than its being actually valued in common by the relevant group of persons.

Both of these theories, as it turns out, are neutral only to a limited range. Neither Rawls's nor Mill's theory is going to be neutral in any sense of the word with respect to, say, the Calvinistic Theory. In this respect, Rawls has not established a theory that is 
preferable because more comprehensively neutral than the theory offered by Mill. In addition, we must understand Rawls as accepting that the defense of an entire political theory is to be made on grounds of its actual acceptance only. 11" From this, it follows that if we are to agree with him we are forced to admit that there is no defense of a liberal conception of justice outside of the specific socio-cultural environment found in modern western countries. This too, I am convinced, does not afford political liberalism any advantage over substantive liberalism.

It might be argued that for all practical purposes, the possibility - afforded by a Millean theory - of a defense of liberalism irrespective of socio-cultural conditions is of limited worth at best. This line of reasoning maintains that, given that there is little to no hope of convincing Calvinists (or other extreme fundamentalists) of the independent truth of the summum bonum as Mill sees it, there is no actual gain to be had in endorsing a Millean theory. When you combine the appreciation of this fact with the acknowledgment that within a liberal culture, Rawls theory might be understood as neutral in a way that Mill's is not (since it relies on no claims as to the intrinsic or supreme value of anything) you discover reason to prefer the Rawlsian approach. But is this right? I think that the answer depends on how you view the difference between how it is that a state that embodies political liberalism and one that embodies substantive liberalism respond to those Calvinists (or would-be Calvinists) among its ranks. Both states will be entirely non-neutral regarding the Calvinists and as a result the Calvinists will not flourish in either. Actually, the Calvinists will have a miserable existence in either state since they will be surrounded by heathens and governed by a state that encourages heathenism. The difference is that within the Rawlsian state the Calvinists will be told that heathenism is exalted - to their demise - not because heathenism is thought right, but only because it is what the heathen majority wants. Since there is no reference to the independent truth of heathenism supporting the Rawlsian state, the arguments made by the Calvinists against this truth will be completely ignored as irrelevant." In the Millean state, on the other hand, the Calvinists will be told that their demise is grounded in the truth of heathenism and in this there is at least some voice 
afforded to the Calvinists. Their arguments may not be convincing in the substantively liberal state but they will not be seen as irrelevant and therefore out of place in political debate. This, I want to suggest, is an advantage for the Millean theory.

Finally, if Mill's substantive liberalism is ultimately to be preferred, this will be on the basis of reasons that are as independent of these practical considerations as possible. If Mill is right this will be because there is such a thing as the summum bonum and he understands it correctly. Mill's rightness will not be grounded merely in the fact that his state affords some minimal amount of respect towards those who fail to appreciate the summum bonum. If Rawls's account is to be preferred, however, it seems unavoidable that this can only be on the basis of practical advantages since Rawls so strongly eschews any justification grounded in the independent truth of any claims to goodness. Once we come to realize that there are no decisive practical advantages to Rawls's political liberalism, there seems to be nothing left to recommend it.

\section{Notes}

I Neutrality is, of course, a vague notion. It is at first understood as something like a right impartiality, or as involving a compatibility with competing points of view or being the realization of a principle demanding fairness and placing constraints against dogmatism. In different developments of the principle of neutrality the concept becomes more sophisticated and varieties of neutrality emerge. For discussion and examples of this variety see Kymlicka, Will, "Liberal Individualism and Liberal Neutrality," Ethics 99, July, 1989. pp. 883-905; Rawls, John, "The Priority of Right and Ideas of the Good," Philosophy and Public Affairs, 17:251-276; De Marneffe, Peter, "Liberalism, Liberty and Neutrality," Philosophy and Public Affairs, 19(3) pp. 253-274, Summer 1990; and Dworkin, Ronald, A Matter of Principle - ch. 8. Cambridge: Harvard University Press, 1985. At this point I am concerned only with the general and admittedly vague notion of neutrality and especially with the justification of neutrality in any form. For the moment I want to avoid digressing into a discussion of the various more precise forms of neutrality.

2 Rawls, John, "The Priority of Right and Ideas of the Good," pp. 260-263.

${ }^{3}$ Rawls discusses two other ways of understanding neutrality of aim. One involves the state's ensuring equal opportunity for the advancement 
of any conception of the good. The other involves avoiding the consequence that some conceptions better flourish or are more likely to better flourish. This last understanding of neutrality is often referred to as consequential neutrality or neutrality of effect. Rawls dismisses both of these sorts of neutrality: the first because some conceptions of the good plainly ought not to be allowed to flourish (i.e. one that values violence intrinsically) and the second because for any state some conceptions will and some will not flourish in part as a consequence of the character of that state. I agree with Rawls on his assessment of these two understandings of neutrality as unimportant for liberal theory and so I leave them out of further discussion.

${ }^{4}$ Rawls, "The Priority of Right and Ideas of the Good," pp. 261-262. 5 ibid., p. 263.

6 Whether Mill understands this neutrality as a neutrality of effect, or as a neutrality only in terms of the state's being restricted against choosing any institution or policy for the reason that it promotes some particular plan of life is a matter of debate that, for our purposes, need not be settled here. It is enough to acknowledge that one can consistently maintain a Millean perspective together with the preferred interpretation of neutrality of aim.

7 One consequence of allowing for this interpretation of procedural neutrality is that we must accept that some defenses of intolerant policies on the basis of some other conceptions of the summum bonum (for example a conception that understood blind and constant obedience to God as the highest good for all humans) are made in a way that involves procedural neutrality. Only such conceptions of the summum bonum that disqualified certain persons or classes of persons as capable of realizing the summum bonum would fail to be procedurally neutral since this justificatory value, so understood, would not be (in any sense) a value shared by everyone affected.

8 Mill, J.S., from On Liberty, in Utilitarianism, On Liberty, Considerations on Representative Government. Edited by Geraint Williams, The Everyman Library edition, J.M. Dent, 1993. London. pp. 129-130.

"Rawls, “The Priority of Right..." p. 263.

10) Jurgen Habermas is also concerned with this feature of Rawls's political liberalism. He raises this objection in the essay "Reconciliation through the Public Use of Reason: Remarks on John Rawls's Political Liberalism.” The Journal of Philosophy, vol. XCII, no. 3, March, 1995.

"1 This feature of Rawls's theory (as well as other formulations of non-substantive liberalism) has been criticized by both feminists and communitarians. The concern is with the limitation on justification in 
political debate in such a way that no reference to the intrinsic value of anything can be legitimately made in defense of a position. Regarding this point, critics have been especially concerned with Rawls's account (and its consequences for his political theory) of the "political conception of the person," found in his book: Political Liberalism, Columbia University Press, New York, 1993, see esp. pp. 29-35; and in his article: "Justice as Fairness: Political Not Metaphysical." From Philosophy and Public Affairs 14, 1985. pp. 223-251. For the criticism see: Sandel, Michael, Democracy's Discontent, The Belknap Press, Cambridge, MA, 1996, see esp. pp. 17-24 and 103-108; Benhabib, Seyla, Situating the Self, Routledge, New York, 1992, ch. 5; and Fraser, Nancy, Justice Interuptus, Routledge, New York, 1997, ch. 3. Fraser is concerned in this chapter with the problematic distinction between public and private and not with Rawls specifically. 